Portland State University

PDXScholar

$11-2015$

\title{
Measuring Risk Preferences in Rural Ethiopia: Risk Tolerance and Exogenous Income Proxies
}

\author{
Ferdinand M. Vieder \\ University of Reading \\ Abebe D. Beyene \\ Environmental Economics Policy Forum for Ethiopia \\ Randall Bluffstone \\ Portland State University, bluffsto@pdx.edu \\ Sahan T.M. Dissanayake \\ Portland State University, sahan@pdx.edu \\ Zenebe Gebreegziabher \\ Colby College
}

See next page for additional authors

Follow this and additional works at: https://pdxscholar.library.pdx.edu/econ_fac

Part of the Economics Commons

Let us know how access to this document benefits you.

\begin{abstract}
Citation Details
Vieider, Ferdinand, Abebe Beyene, Randall Bluffstone, Sahan Dissanayake, Zenebe Gebreegziabher, Peter Martinsson, and Alemu Mekonnen. "Measuring Risk Preferences in Rural Ethiopia: Risk Tolerance and Exogenous Income Proxies." (2015).
\end{abstract}

This Working Paper is brought to you for free and open access. It has been accepted for inclusion in Economics Faculty Publications and Presentations by an authorized administrator of PDXScholar. Please contact us if we can make this document more accessible: pdxscholar@pdx.edu. 


\section{Authors}

Ferdinand M. Vieder, Abebe D. Beyene, Randall Bluffstone, Sahan T.M. Dissanayake, Zenebe Gebreegziabher, Peter Martinsson, and Alemu Mekonnen 


\title{
Measuring risk preferences in rural Ethiopia: Risk tolerance and exogenous income proxies*
}

\author{
Ferdinand M. Vieider ${ }^{\dagger} \quad$ Abebe Beyene $e^{\ddagger} \quad$ Randall Bluffstone ${ }^{\S}$ \\ Sahan Dissanayake $\quad$ Zenebe Gebreegziabher ${ }^{\|} \quad$ Peter Martinsson** \\ Alemu Mekonnen ${ }^{\dagger \dagger}$
}

November 20, 2015

\begin{abstract}
Risk-aversion has generally been found to decrease in income. This may lead one to expect that poor countries will be more risk-averse than rich countries. Recent comparative findings with students suggest the opposite, potentially giving rise to a risk-income paradox. Findings with students, however, may result from selection effects. We test whether a paradox indeed exists by measuring the risk preferences of over 500 household heads representative of the highlands of Ethiopia. We find high degrees of risk tolerance, consistent with the evidence obtained for students. We also find risk tolerance to increase in income proxies, thus completing the paradox. Using plausibly exogenous income proxies allows us to conclude that part of the causality must run from income to risk tolerance. It also avoids problems with measurement of income in developing countries that may have led to attenuation bias in some studies. Our findings further suggest that risk preferences cannot be blamed for the failure to adopt new technologies. Alternative explanations are discussed.
\end{abstract}

Keywords: risk preferences; development; experimental methodology

JEL-classification: C93; D03; D80; O12

${ }^{*}$ This study was financed by the World Bank's Knowledge for Change Program and the Trust Fund for Environmentally and Socially Sustainable Development. The views expressed in the paper are the authors' alone and should not be attributed to the World Bank or its member countries. We would like to thank Glenn Harrison, Tobias Schmidt, Roel van Veldhuizen, and seminar pariticpants at the SEEDEC conference in Bergen and the CEAR-CSAE workshop at the University of Oxford for helpful suggestions. All errors remain ours alone.

${ }^{\dagger}$ Corresponding author: University of Reading, Department of Economics, UK; and WZB Berlin Social Science Center, Risk \& Development Group, Germany. Email: f.vieider@reading.ac.uk; Tel: +44-118-3788208

${ }^{\ddagger}$ EfD Ethiopia

$\S$ Portland State University, USA

^Colby College, USA

"Mekelle University, Ethiopia

${ }^{* *}$ University of Gothenburg, Sweden

${ }^{\dagger \dagger}$ Addis Ababa University, Ethiopia 


\section{Introduction}

Uncertainty is a central fact in economic activity, and human life more in general. Rural people in developing countries are especially exposed to the vagaries of fate, since their largely agricultural income strongly depends on highly variable weather patterns and formal insurance against catastrophic events rarely exists. Nevertheless, our understanding of risk preferences and the role they play in the lives of rural populations in developing countries is still limited.

Poor inhabitants of developing countries have long been considered to be very risk averse (see Haushofer and Fehr, 2014, for a recent review). This conclusion is mostly based on the fundamental economic intuition that risk aversion should decline in wealth or income (Arrow, 1970; Gollier and Pratt, 1996). This intuition has indeed found considerable empirical support within various countries in the West (Donkers, Melenberg and Van Soest, 2001; Dohmen, Falk, Huffman, Sunde, Schupp and Wagner, 2011), although the evidence is less uniform than one might think (see Hopland, Matsen and Strøm, 2013, for a recent review). ${ }^{1}$

The evidence for developing countries is even less clear. Binswanger (1980) famously found no correlation between risk aversion and wealth, and Tanaka, Camerer and Nguyen (2010) found a correlation only with average village income but not with personal income, and only for some parameters. Yesuf and Bluffstone (2009) found risk aversion to decrease in the availability of cash in Ethiopia, and Liebenehm and Waibel (2014) found the risk aversion of cattle farmers in Burkina Faso and Mali to decrease in income. Gloede, Menkhoff and Waibel (2013) found risk tolerance to increase with income in two large rural samples in Thailand and Vietnam. Cardenas and Carpenter (2013), however, found no correlation between risk preferences and economic well-being (an aggregate measure of several wealth indicators) in an experiment in six Latin-American

\footnotetext{
${ }^{1}$ Even though there is considerable support for this hypothesis, not all studies find clear-cut evidence for the relationship. For instance, and von Gaudecker, van Soest and Wengström (2011) only found the correlation for gain-loss prospects, and not for pure gain prospects (see also Booij, Praag and van de Kuilen, 2010). Harrison, Lau and Rutström (2007) even found an effect to the contrary in the Danish population, while Noussair, Trautmann and van de Kuilen (2014) found a significant effect of income in a representative sample of the Dutch population only after controlling for household wealth.
} 
countries.

Measurements of risk preferences in developing countries have also often confirmed high degrees of risk aversion on average (Binswanger, 1980; Liebenehm and Waibel, 2014; Yesuf and Bluffstone, 2009). They did, however, generally employ tasks that are seldom - if at all-used in the West, which makes comparisons difficult. The choice lists employed are further asymmetric, limiting the degree of risk seeking they can detect. Especially in the presence of noise, such asymmetric choice lists may result in the systematic overestimation of risk aversion (Andersson, Tyran, Wengström and Holm, 2015). If some subjects decide purely randomly, their choices may be counted towards risk aversion in lists that are skewed towards the detection of the latter. In particular, the Binswanger task is cut off at risk neutrality, so that any random choice would be counted towards risk aversion. Using simulations as well as experimental data, Crosetto and Filippin (2015) showed that Binswanger-style lists overestimate risk aversion, and that noise indeed compounds this overestimation - a problem that may be particularly important in samples with low education levels.

In contrast to the high risk aversion found in these studies with rural populations, recent cultural comparisons of risk preferences using student samples and employing the exact same experimental tasks across a large number of countries have found risk aversion to be considerably lower in developing countries than in rich, developed countries (Rieger, Wang and Hens, 2014; Vieider, Lefebvre, Bouchouicha, Chmura, Hakimov, Krawczyk and Martinsson, 2015). Taken together with the prevalent within-country result of risk aversion decreasing in income, the finding of risk aversion increasing in income per capita between countries suggests a risk-income paradox (Vieider, Chmura and Martinsson, 2012). Since these comparative results were obtained with students, however, it remains unclear whether they may be due to a selection effect, whereby in poorer countries children from relatively more affluent families attend universities. In that case, rather than finding a paradox, we might just observe systematic selection effect.

In this paper, we test whether the between country results obtained with students extend to a representative sample of the rural population of Ethiopia. 
While students constitute a relatively homogeneous group in terms of observable characteristics, a comparison in terms of average risk preferences of the general population nevertheless promises to shed some light on the importance of selection effects in students (Andersen, Harrison, Lau and Rutström, 2010). We measure the risk preferences of a large sample of the Ethiopian rural population, covering regions of rural Ethiopia encompassing about $80 \%$ of the Ethiopian population and $70 \%$ of its landmass. We focus on the rural population, inasmuch as $81 \%$ of the population of Ethiopia lives in rural areas (World Bank data for 2013), and rural populations have been described as particularly risk averse in previous research (Haushofer and Fehr, 2014), so that they constitute a stronger test for our hypothesis than urban populations. Notwithstanding some growth over the last decade, Ethiopia remains one of the poorest countries in the world, with a GDP per capita of $\$ 1354$ in 2013 using PPP. This makes the sample an ideal testbed for whether the findings with students extend to poor countries.

We measure risk preferences using choice lists between lotteries or prospects and sure amounts of money. These tasks are commonly used in the West (Abdellaoui, Baillon, Placido and Wakker, 2011; Bruhin, Fehr-Duda and Epper, 2010; Tversky and Kahneman, 1992), and have the advantage of being comparable to the above-mentioned evidence collected with students. This will allow us to assess whether the different results described above are due to differences in elicitation tasks or differences in subject pools. We further obtain several measurements of risk preferences for each person, allowing us to econometrically separate risk preferences from noise. This may be important, as noise in the measurement of risk preferences may be one of the factors affecting correlations with income in previous investigations.

Obtaining good income measures is often not trivial for the subsistence farmers that make up most of our sample - a fact that may contribute to the inconsistent evidence on the risk-income relationship (correlations with wealth, which is easier to measure, tend to be weaker and less consistent in general). Instead of measuring income directly, we thus recur to income proxies such as land size and altitude, which have been found to correlate strongly with income in agricultural 
populations. This reduces measurement problems, and has the further advantage that such income proxies can be plausibly considered as exogenous, allowing us to make inferences on the direction of causality. Indeed, causal evidence on the risk-income relationship remains scant (see below for a discussion), possibly because economists have long considered risk preferences to be innate - a stance that is now increasingly being abandoned (see e.g. Zilibotti and Doepke, 2012, for a discussion of this point). ${ }^{2}$

We find that the rural population of Ethiopia is highly risk tolerant, thus departing from traditional conclusions about developing country samples. At the same time, we find a strong correlation of risk tolerance with income proxies, indicating that more affluent households exhibit higher risk tolerance. By restricting our attention to exogenous income proxies, we then provide some evidence on a causal effect from income to risk preferences. Finally, we discuss the implications of our findings in terms of the failure to adopt new technologies by poor households in developing countries, which has often been blamed on low risk tolerance. Given the high levels of risk tolerance we find in the aggregate, such an account does no longer seem to hold up (although the explanation may remain valid for the poorest and most vulnerable households within our sample).

This paper proceeds as follows. Section 2 describes the subject pool and provides details on the experimental tasks and procedures, as well as discussing data quality. Section 3 presents the results. We start out by presenting some non-parametric data at the aggregate level, and then discuss the stochastic assumptions and econometric methods used to fit functional forms to the data. Then we look at correlations with socio-economic variables, in particular income proxies and indicators of socio-economic conditions in childhood. Finally section 5 discusses the results and concludes the paper.

\footnotetext{
${ }^{2}$ One of the reasons why innate preferences are unlikely to be the full story is the increasing evidence for a role of socialization in the detrmination of preferences. For instance, Booth and Nolen (2012) showed that girls are less risk averse when coming from an all girls school relative to a coed school, or when they are randomly assigned to an all-female group than when assigned to a mixed-sex group. Bacon, Conte and Moffatt (2014) showed further that the correlation in risk preferences within couples increases with years of marriage, thus indicating a role of assimilation in addition to associative mating.
} 


\section{Experimental setup}

\subsection{Subject pool characteristics}

A total of 504 household heads were recruited in three regions in the Ethiopian highlands. ${ }^{3}$ The study was carried out in the context of an investigation of the effectiveness of improved cookstoves under the REDD + program (a United Nations program aimed at reducing emissions from deforestation). This focus also determined the stratification technique used to select the sample. Subjects were selected from the three regions involved based on forest cover, with $20 \%$ of subjects from Amhara, 50\% from Oromia, and 30\% from the Southern Nations, Nationalities and Peoples Region (SNNP; out of the total population of the three regions, Amhara makes up approximately 29\%, Oromia 46\%, and SNNP 15\%, so that Amhara is slightly undersampled). These regional states represent $80 \%$ of the population and over $70 \%$ of the land area of Ethiopia.

Thirty-six villages (locally called Got or sub-Kebele) were randomly selected from the three regions from a list of 110 villages previously selected by the Ethiopian Development Research Institute $(E D R I)$ to collect forestry data. Out of the 110 sites, we removed 15 sites that were covered during a pilot survey conducted to inform our research. We also removed all sites from Tigrai Regional State, as this state was less interesting in terms of the REDD + questions asked in the study. We then randomly selected 36 villages from the remaining list. For each of these villages, a list of households was obtained from the local administration. Subsequently, 14 households were randomly picked from each village using systematic random sampling. This ensured a sample size that could be covered with our research budget, while at the same time ensuring wide geographical coverage. The data were collected by a total of 25 fieldworkers ( 5 supervisors and 20 enumerators) who were extensively trained on the experiments. The supervisors

\footnotetext{
${ }^{3}$ The exclusive use of household heads is unlikely to significantly affect our conclusions. Studying 347 rural Ethiopian couples, Di Falco and Vieider (2015) show that spouses' risk preferences are not significantly different from those of their husbands (although female household heads are much more risk averse than male household heads). This is also consistent with a recent meta-analysis by Filippin and Crosetto (2015), who show that gender differences are task specific and may be weaker than thought.
} 
all held a BSc degree and were experienced in field survey work. The enumerators and supervisors were selected so that they were able to speak the local languages. The experimental procedures were refined in a pilot before starting the actual experiment, which also gave the enumerators a chance to train on the tasks. Supervisors paid particular attention to making the enumerators follow standardized procedures. ${ }^{4}$

The average age of our subjects is 42.13 years (SD: 13.2), with a range between 20 and 90 years. Since the study was targeted at household heads, $89.9 \%$ of respondents are male. At $91 \%$ the overwhelming majority of our subjects work mainly in the agricultural sector, with the second largest group consisting of women doing house work (5\%), and the third largest of people owning a business $(2 \%)$. The median household has about 1.5 ha (about 3 acres) of land. About $38 \%$ of the respondents are illiterate, with the literate subjects having mostly only primary education ( $45 \%$ of the sample).

\subsection{Experimental tasks and explanations}

We measure risk preferences using certainty equivalents $(C E s)$. CEs are easy to construct and to deploy. Physical representations of the choice problems are straightforward. In contrast to tasks such as the one popularized by Holt and Laury (2002), which have been found to result in high rates of inconsistencies (Charness and Viceisza, 2012; Lönnqvist, Verkasalo, Walkowitz and Wichardt, 2011), only monetary amounts vary within a given choice list, while probabilities stay fixed. This makes it easy to lay out money on a table and represent probabilities physically, which is a great advantage given people's familiarity with money. CEs can also easily be used to estimate one's favorite decision model (although more CEs are typically required for more complex models). Finally, while they allow for structural model estimation, they are also straightforward to analyze non-parametrically. ${ }^{5}$

\footnotetext{
${ }^{4}$ Since several languages needed to be covered, the assignement of enumerators to villages was not randomized, so that we cannot control for enumerator fixed effects in our regressions.

${ }^{5}$ Some scholars have raised doubt on whether CEs are 'realistic' in the sense of modelling real world decision processes, based on the observation that real choices occur between risky alternatives. We are unconvinced of this argument. For one, many choices in the real world do
} 
In a typical task or choice list, a subject is offered repeated choices between a lottery or prospect and different sure amounts of money. The prospect offers a probability $p$ of obtaining a prize, $x$, or else an outcome $y$ with a complementary probability $1-p$. We will represent such a prospect as $(x, p ; y)$. The sure amounts $s_{j}$ are always included between the prize and the low outcome of the prospect, i.e. $x \geq s_{j} \geq y$. The extreme outcomes of the prospect, $x$ and $y$, are explicitly included in the list of sure amounts to serve as a rationality check. If such extremes are not included and subjects always choose either the prospect or the sure amount (i.e., they never switch), it may be difficult to determine whether this is due to true preferences or to a misunderstanding of the task. As long as preferences are consistent, i.e. subjects switch only once (see below), the certainty equivalent can then be taken to be the mean between the first sure amount that is chosen over the prospect, and the last sure amount for which the prospect was preferred over the safe option.

In this experiment, we fix the prize of the prospect at 40 Birr and the lower outcome at 0 throughout. The prize of 40 Birr corresponds to about US $\$ 6$ in purchasing power parity (World Bank 2013), for an overall expected payoff from participating equal to $\$ 3 \mathrm{PPP}$ for a risk neutral participant. Considering that most of our subjects live on less than two Dollars a day, the money at stake was significant and well in line with stakes in similar experiments (Attanasio, Barr, Cardenas, Genicot and Meghir, 2012; Yesuf and Bluffstone, 2009). We used a total of 7 choice lists, which offered a prize of 40 Birr with probabilities of $p=\{0.05,0.10,0.30,0.50,0.70,0.90,0.95\}$, and which were administered in random order. Using several choice lists has the advantage that noise can be easily separated from preference parameters in the econometric analysis.

The sure amounts increased from 0 to 40 Birr (included) in steps of 1 Birr. Having a relatively small resolution again reduces noise, as can thus assign risk preferences to subjects with a higher degree of precision (Crosetto and Filippin,

indeed involve tradeoffs between sure amounts and risky options (e.g., the decision whether to pay a sure amount of money for fertilizer to invest in a risky payoff from agriculture that may depend on other variables such as rainfall). Ultimetely, the question of external validity is one that needs to be addressed empirically, and no conclusive evidence on this point exists to date. 
2015). Probabilities were implemented using 20 ping-pong balls, with balls of different colors associated to the high and low outcomes. The composition of balls was physically shown to subjects for each choice list. We chose to keep outcomes fixed across choice lists while changing probabilities, as we believe that for typical experimental stakes most of the interesting patterns emerge along the probability dimension (see also Fehr-Duda and Epper, 2012, on this point). This will restrict our model to one subjective dimension, so that more complex models which allow for two subjective dimensions, such as prospect theory, cannot be estimated based on our data. This methodology can, however, easily be expanded to the latter. ${ }^{6}$

Subjects were initially asked whether they consented to take part in the study. They were explained that the study consisted of various parts, including a questionnaire, and an experimental game. Before beginning the actual experiment, subjects were carefully explained the process. All explanations and subsequent elicitations took place in individual interviews. Subjects were shown how the urn was composed. They were then shown the prospect, which was explained by laying out banknotes next to the associated colored ping-pong balls used as chance device. Subjects were asked to choose between this prospect and the sure amount, also physically laid out next to the prospect. The enumerator introduced the example by explaining the entire choice list. Subjects were then asked for their choice between the prospect and 0 Birr for sure; and then for their choice between the prospect and 40 Birr for sure. Given that for the first everybody ought to prefer the prospect and for the second everybody ought to prefer the sure amount, this quite naturally conveys the idea that subjects should only switch once (which was not enforced in case subjects still wanted to switch to and fro in the experiment).

Once a subject had understood this process, the enumerator began eliciting the preferences for different probability levels in random order. This random or-

\footnotetext{
${ }^{6}$ In particular, some choice tasks varying outcomes at a given probability are needed to separate utility curvature from probability transformation in the econometric analysis. To obtain good power for the observations, prospects with a non-zero lower outcome are necessary in addition to varying upper outcomes.
} 
der had been predetermined, and each enumerator could read the order from the interview sheet (there were 14 different orders in total). Since the outcomes stayed the same throughout the experiment, the enumerator only needed to change and explain the color composition of balls from one task to the other. While enumerators were instructed to ask for a preference for each of the 41 sure amounts, in some instances participants would say that their preferences would stay the same for all higher amounts, or would even directly indicate where they wanted to switch from the prospect to the sure amount. In such cases, the enumerators were instructed to simply encode this switching point directly. The total experiment including the explanations took about 30-40 minutes on average. ${ }^{7}$

At the end of the risk experiment, one of the choice lists was randomly selected for real play - the standard procedure in this kind of experiment (Cubitt, Starmer and Sugden, 1998). In that choice list, one choice between a given sure amount and the prospect was then extracted for play, so that overall each decision had the same probability of being played for real. This procedure had been thoroughly explained to subjects while presenting the example at the beginning of the experiment. Subjects were explicitly asked to repeat the randomization procedure to the enumerator before starting with the actual experiment. Subjects were also told explicitly that, given this procedure, it was in their best interest to treat every single decision as if it were the one that would be played for real money at the end.

\subsection{Data quality}

The overall data quality is reasonably good. Only 3 out of 504 subjects, or $0.6 \%$ of our sample, switched multiple times from the prospect to the sure amount and back in the choice lists. We will exclude these subjects from the analysis, leaving us with 501 subjects. A further test of rationality are what we call strong violations of first order stochastic dominance, consisting in a preference for 0 Birr for sure over playing the prospect, or of playing the prospect over 40 Birr for

\footnotetext{
${ }^{7}$ This 40 minute period excludes the time needed for the questionnaire, which was asked in a separate instance.
} 
sure. No subject preferred the sure 0 Birr to the prospect. On the other hand, 4 subjects, or $0.8 \%$ of the sample, indicated a preference for the prospect over 40 Birr for sure in at least one of the choice lists. These subjects will also be excluded from the analysis. Finally, for one subject we do not have responses to the questionnaire, leaving us with a total of 496 subjects.

We next look at (ordinary) violations of stochastic dominance. Such a violation occurs whenever a subject indicates a certainty equivalent for a given prospect that is lower than the certainty equivalent indicated for another prospect offering a lower probability of obtaining the same prize, $C E\left(p_{j}\right)<C E\left(p_{i}\right)$, $p_{j}>p_{i}$. About $38 \%$ of our subjects violate stochastic dominance at least once. Seen that most violations are relatively small in terms of amounts, this appears to lie within acceptable bounds, considering also the random ordering of the tasks. Vieider, Truong, Martinsson and Pham Khanh (2013) found that about 25\% of Vietnamese farmers violated stochastic dominance in a similar setting using a fixed ordering of tasks. Looking at total choices, our subjects violate first order stochastic dominance in $5.4 \%$ of choices overall. Overall, we thus conclude that the data are reasonably consistent, but that controlling for noise in the analysis will be important.

\section{Aggregate data and modeling approach}

\subsection{Non-parametric representation of aggregate data}

We start by conveying a feel for the data through non-parametric summary statistics for the different prospects, shown in table 1. Taking the mean CE over all the prospects (shown in the last row of the table), we find that subjects are on average significantly risk seeking. Looking at individual prospects, we see that subjects are risk seeking for small probabilities and risk averse for large ones, as has typically been found in the literature. However, the risk seeking behavior prevails up to and including a probability of $p=0.5$, which is much higher than has been found in the West. This serves to exclude explanations purely based on psychological factors that may lead subjects to switch closer to the middle of the 
list - a point to which we will return once we fit functions to the data.

The findings are, on the other hand, consistent with recent findings across 30 countries with students using the same type of tasks reported by Vieider et al. (2015). This confirms that subjects in poor countries tend to be considerably more risk tolerant than subjects in industrialized countries, and that this finding remains valid beyond students subject pools.

Table 1: Summary measures of aggregate risk preferences by prospect

\begin{tabular}{rrrrc}
\hline prob. & median CE & mean CE & SD & test $=\mathrm{EV}$ \\
\hline 0.05 & 7.5 & 10.88 & 10.37 & $z=18.21, p<0.001$ \\
0.10 & 9.5 & 13.53 & 10.19 & $z=17.84, p<0.001$ \\
0.30 & 15.5 & 18.05 & 10.05 & $z=11.51, p<0.001$ \\
0.50 & 22.5 & 23.01 & 9.12 & $z=6.26, p<0.001$ \\
0.70 & 29.5 & 27.13 & 8.58 & $z=-1.49, p=0.136$ \\
0.90 & 34.5 & 32.01 & 8.51 & $z=-7.33, p<0.001$ \\
0.95 & 37.5 & 34.38 & 8.17 & $z=-6.54, p<0.001$ \\
\hline mean & 22.07 & 22.71 & 7.30 & $z=8.19, p<0.001$ \\
\hline
\end{tabular}

We can now show how our data fit into different models in a purely nonparametric way. Finding a good descriptive model to fit the data is important inasmuch as this will improve our econometric analysis of the determinants of preferences, reducing potential attenuation bias. We further discuss our modeling assumptions in some detail, as they will determine our choice of functional forms to be used, and since not all readers of development papers may be deeply familiar with the concepts and models employed. Since the data patterns we find are relatively complex, they cannot be explained by one simple measure of risk aversion. The use of overly simple measures of risk preferences may indeed be partially to blame for past null findings in correlation analysis, as such measures may confound actual preferences with noise.

We start with an expected utility $(E U)$ model. Since utility functions are unique only up to an affine transformation, we can arbitrarily fix the endpoints at $u(y) \equiv 0$ and $u(x) \equiv 1$. Plugging this into the general equivalence $u\left(C E_{i}\right)=$ $p_{i} u(x)+\left(1-p_{i}\right) u(y)$, we now simply obtain that $u\left(C E_{i}\right)=p_{i}$. The non-parametric mean utility function thus obtained is plotted in figure 1(a). This utility function resembles the one proposed by Markowitz (1952). Markowitz recognized that 
people may be risk seeking for some prospects while being risk averse for others, so that the utility function would have convex as well as concave sections. To accommodate this finding, he proposed to abandon initial wealth integration and to instead measure utility though changes of wealth. ${ }^{8}$ This type of referencedependence has by now been widely integrated into EU models (Diecidue and van de Ven, 2008; Kőszegi and Rabin, 2007; Sugden, 2003; von Gaudecker et al., 2011).

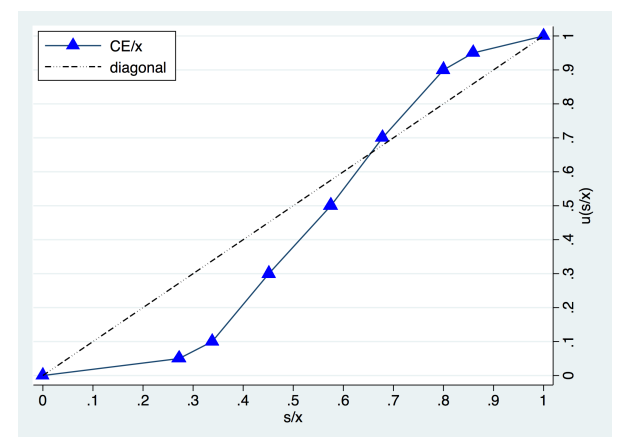

(a) Nonparametric EU function

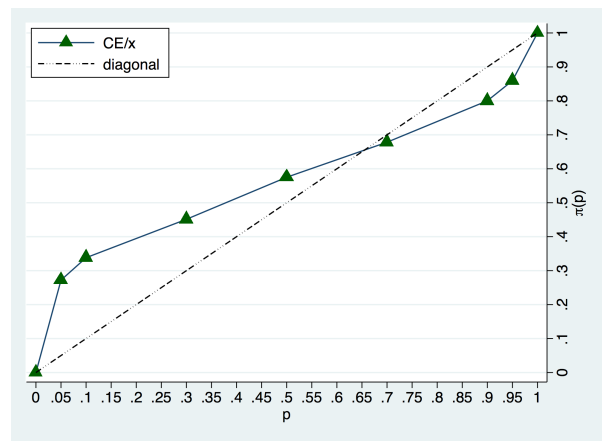

(b) Nonparametric Dual function

Figure 1: Non-parametric functions

Markowitz based the derivation of this type of utility function on a simple thought experiment. In this experiment, he asked readers about their choices between a prospect offering a prize $x$ with probability $p=0.1$ or else nothing and the expected value of the prospect. For small $x$, most people would likely choose the prospect (e.g., most people would prefer a prospect offering a one in ten chance of $\$ 10$ over $\$ 1$ for sure). As $x$ got larger, however, people would gradually switch to preferring the sure amount (e.g., most people would prefer a sure $\$ 1,000,000$ over a prospect offering a one in ten chance at $\$ 10,000,000$ ).

In our case, however, we kept the amounts fixed, and let probabilities vary instead, i.e. we elicited $C E_{i} \sim\left(\bar{x}, p_{i} ; \bar{y}\right)$, where the bar indicates that values are unchanging across choice lists and $\sim$ indicates indifference. One could still perceive such behavior as being driven by the value of the prospect, since the

\footnotetext{
${ }^{8}$ With initial wealth integration, convex and concave sections of the utility function might co-exist at the same point, since the same pattern has been found for all kinds of wealth levels, thus giving rise to inconsistencies.
} 
expected value of the prospect increases with the probability of winning the prize. However, in a seminal paper Preston and Baratta (1948) let both outcomes and probabilities vary systematically across choices. What they observed was that outcome variation had a negligible effect on the data (although the outcomes did obviously not range up to the amounts indicated in Markowitz's thought experiment). Even more importantly, the pattern across different probability levels remained constant, no matter what the outcome level. This pattern gave rise to much experimentation by psychologists in subsequent years, and hit the economic discipline when probability weighting was incorporated into prospect theory jointly with utility transformations and published in Econometrica by Kahneman and Tversky (1979).

This consistent pattern across probabilities, which we also find in our data, suggests a different approach to modeling the choices we observe. One could model risk preferences through a subjective transformation of probabilities into decision weights, rather than a subjective transformation of outcomes into utilities. In other words, we can represent a choice as being linear in outcomes and non-linear in probabilities, such that $C E=\pi(p) x+[1-\pi(p)] y$, where we will impose that $\pi(0) \equiv 0$ and $\pi(1) \equiv 1$. In our case, we can again simply solve this, noting that in our setting $\pi\left(p_{i}\right)=\frac{C E_{i}}{x}$. This non-parametric Dual function is depicted in figure 1(b), and can be seen to exactly mirror the utility function to its left (see Yaari, 1987, for an axiomatization of the Dual function for rank-dependent utility). ${ }^{9}$

Being the dual of each other, the two functions presented above are prima facie perfectly equivalent. Nonetheless, we have a strong preference for the dual function. The experimental stimuli varied probabilities across choice lists. The same type of pattern - combining risk seeking for small and risk aversion for large probabilities - has been found for different outcome levels, which directly contradicts EU with a Markowitz-type utility function (similar violations would

\footnotetext{
${ }^{9}$ One could also think of this model as a prospect theory model with linear utility. Indeed, linearity of utility can often not be rejected in prospect theory models for typical experimental stakes. For instance, Vieider et al. (2013) fail to reject linearity in utility for their Vietnamese farmer sample. Linearity also holds for many (although not all) of the student samples mentioned above - see L'Haridon and Vieider (2015) for details.
} 
be observed for the Dual, if we had used significant variations in outcomes instead). Also, as we will further discuss below, the coexistence of risk seeking and risk aversion requires two-parameter functions to fit the data. Such functions are much more common, and the parameters have a clearer interpretation, under the dual theory than under EU. An analysis using a one-parameter utility function is nonetheless reported in the appendix.

\subsection{Stochastic modeling}

We have so far only derived non-parametric functions from the data. While this involves the least tampering with the data, such an approach completely neglects one of the strengths provided by a multiplicity of observations - the possibility to separate noise from genuine preferences. This will lead to attenuation bias in regression analysis, since the noise in the measurements will affect the correlations with our socio-economic variables. In this section, we will thus try to both reduce the number of parameters needed to describe the data (relative to the seven nonparametric data points), and to develop an explicit stochastic structure that allows us to filter out noise from the observations. Alas, this does not come for free. We will need to add some more assumptions, as well as some complexity to the data estimation. Annotated Stata programs for all estimations in the paper are available for download at www.ferdinandvieider.com.

Following Bruhin, Fehr-Duda and Epper (2010), we econometrically represent decisions directly using the switching points from the prospect to the sure amount. This takes into account the structure of the experimental setup, in which we elicit certainty equivalents for prospects, $c e_{i} \sim \boldsymbol{p}_{\boldsymbol{i}}$, where the subscript $i$ indicates the particular prospect at hand, such that $\boldsymbol{p}_{\boldsymbol{i}}=\left(x, p_{i}\right)$. This approach takes into account that choices within a given choice list are not independent. It is also much more efficient than a discrete choice approach, drastically reducing estimation time. All the results remain stable if a discrete choice approach is used instead.

We start from the observation that at the switching point the utility of the certainty equivalent is by definition equal to the utility of the prospect. Since 
outcomes enter the equation linearly, we can simply write:

$$
\hat{c e_{i}}=\pi\left(p_{i}\right) x+\left[1-\pi\left(p_{i}\right)\right] y=\pi\left(p_{i}\right) x
$$

where $\hat{c e}_{i}$ is the certainty equivalent predicted by our model. This predicted certainty equivalent will not necessarily be equal to the one observed in the actual data. For instance, decision makers may make mistakes when calculating the utility of a prospect, or our model may be mis-specified relative to the true underlying decision process. We can thus represent the relation between the predicted and observed certainty equivalent as follows:

$$
c e_{i}=\hat{c} e_{i}+\epsilon_{i}
$$

where $\epsilon_{i} \sim N\left(0, \sigma^{2}\right)$ is an error term which captures the deviations mentioned above. We can now express the probability density function $\psi($.$) for a given$ prospect $i$ as follows

$$
\psi\left(\theta, \sigma_{i}, \boldsymbol{p}_{\boldsymbol{i}}\right)=\frac{1}{\sigma_{i}} \phi\left(\frac{\hat{c} e_{\theta i}-c e_{i}}{\sigma_{i}}\right)
$$

where $\phi$ is the standard normal density function, and $\theta$ indicates the vector of parameters to be estimated. The subscript $i$ to the noise term $\sigma$ serves to remind us that we allow noise to depend on the characteristics of the single prospect. Since our prospects are, however, invariant except for the probability of winning the prize, this error term simply takes the form $\sigma_{i}=\sigma x$, which serves to standardize the error term of the model. ${ }^{10}$

The parameters of the model can be estimated by maximum likelihood procedures. To obtain the likelihood function per decision maker, we need to take

\footnotetext{
${ }^{10}$ Many other specifications are conceivable in principle, but a thorough investigation is beyond the scope of this paper. Wilcox (2011) proposed a contextual utility specification, whereby the error term is made to depend on the difference in utility between the highest and lowest outcome in the prospect. Notice that we are fulfilling this criterion, since in our setup either utility is linear or the utility endpoints are normalized to 0 and 1 , and such endpoints are invariant across choice lists. In any case, the type of choice representation used here is not subject to the criticism by Wilcox - see Apesteguia and Ballester (2014) for a discussion.
} 
the product of the density functions above across prospects:

$$
L(\theta)=\prod_{n=1}^{N} \prod_{i} \psi\left(\theta_{n}, \sigma_{n i}, \boldsymbol{p}_{\boldsymbol{i}}\right)
$$

where $\theta$ is the vector of parameters to be estimated such as to maximize the likelihood function. The subscript $n$ to $\theta$ indicates that we will allow the estimated parameters to be linear functions of observable characteristics of decision makers in the regression analysis, such that $\hat{\theta}=\hat{\theta}_{k}+\beta X$, where $\hat{\theta}_{k}$ is a vector of constants and $X$ represents a matrix of observable characteristics of the decision maker. The subscript $n$ to the noise term $\sigma$ indicates that the error is also made to depend on the observable characteristics of the decision maker. ${ }^{11}$

Taking logs, we obtain the following log-likelihood function:

$$
L L(\theta)=\sum_{n=1}^{N} \sum_{i} \ln \left[\psi\left(\theta_{n}, \sigma_{n i}, \boldsymbol{p}_{\boldsymbol{i}}\right)\right]
$$

We estimate this function in Stata 12 using the Broyden-Fletcher-GoldfarbShanno optimization algorithm. Errors are always clustered at the subject level.

\subsection{Aggregate data fitting}

We are now ready to fit functional forms to our preference data. In figure 2 we fit a 2-parameter function developed by Prelec (1998) to the data, which takes the form $\pi(p)=e^{-\beta(-\ln (p))^{\alpha}}$. The estimated parameters are $\alpha=0.538(s e=0.013)$, $\beta=0.703$ (se $=0.009)$, and $\sigma=0.233$ (se =0.002). The result is vastly superior to to the fit of Prelec's 1-parameter function characterized by $\beta \equiv 1$, thus making the additional parameter worthwhile $\left(\chi^{2}(1)=646.95, p<0.001\right.$, likelihood ratio

\footnotetext{
${ }^{11}$ Yet a different approach would be to estimate a mixture model, allowing for heterogeneity in modelling assumption. Harrison, Humphrey and Verschoor (2010) do so for several different countries in the developing world. Notice, however, how we could not use these methods to distinguish between EU and dual-EU, as they model the same processes through different parameters. While such methods could be used to distinguish between one- and two-parameter functions, one-parameter functions are a special case of the two-parameter setup in our case. Directly estimating the two-parameter function thus facilitiates the interpretation of regression results, without losing any generality in terms of modeling.
} 
test). ${ }^{12}$ An analysis using a 1-parameter EU function is provided in the appendix.

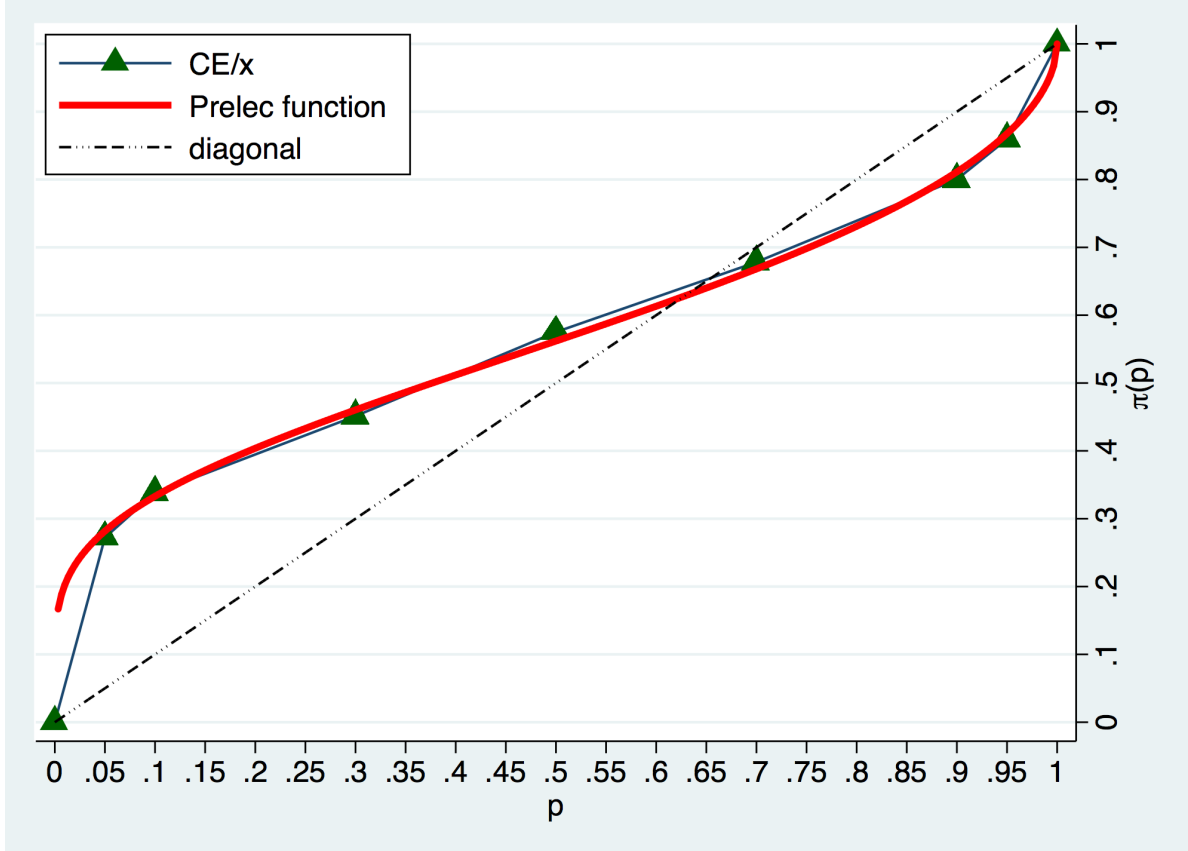

Figure 2: Fitting 2-parameter functions to the data

The parameters of the Prelec function have a precise behavioral interpretation. A parameter combination of $\alpha=1$ and $\beta=1$ in combination with linear utility indicates expected value maximization. The parameter $\beta$ mostly governs the elevation of the function, with values $>1$ indicating a more depressed function and thus risk aversion under linear utility, and values $<1$ indicating a more elevated function, and hence risk seeking. When $\alpha=1, \beta$ can thus be considered a measure of standard risk aversion. The parameter $\alpha$ governs mostly the slope of the curve, with values $<1$ indicating probabilistic insensitivity, i.e. CEs that change less than proportionately with probabilities. This is a phenomenon whereby people attribute greater weight to a given change in probability if it happens towards the endpoints of the scale close to $p=0$ or $p=1$ than if the same probability change occurs in an intermediate region. It is one of the most established findings in the prospect theory literature (Abdellaoui, 2000; Bleichrodt and Pinto, 2000; Wu and Gonzalez, 1996). Since linear probability weighting is

\footnotetext{
${ }^{12}$ The parameters of the 1-parameter function are $\alpha=0.572(s e=0.013)$ and $\sigma=0.256$ $(s e=0.003)$. This function has a fixed crossing point of the diagonal at $1 / e=0.37$. Other 1-parameter and 2-parameter functional forms perform similarly.
} 
considered to be normative (Wakker, 2010), probabilistic insensitivity is often perceived as a rationality failure (Tversky and Wakker, 1995). ${ }^{13}$ We will refer to the two parameters as the risk aversion and the sensitivity parameter respectively.

\section{Risk preferences and socio-economic conditions}

\subsection{Parametric analysis}

We are now ready to examine the correlation of our measures with several characteristics of interest using our structural model (a non-parametric stability analysis is provided in the next section). We start by looking at indicators of wealth and income. Especially in developing countries there is a dearth of evidence on the effect of income, probably because good income measures are difficult to come by amongst the poor inhabitants of the rural regions of developing countries, who more often than not are subsistence farmers.

Table 2: Summary statistics of main regressors

\begin{tabular}{lcccc}
\hline & mean & SD & min & $\max$ \\
\hline land size (hectares) & 1.80 & 1.61 & 0 & 10.5 \\
altitude (meters) & 2218 & 337.31 & 1437 & 3150 \\
age (years) & 42.13 & 13.14 & 20 & 90 \\
literate & 0.453 & 0.498 & 0 & 1 \\
middle school & 0.169 & 0.375 & 0 & 1 \\
female & 0.101 & 0.301 & 0 & 1 \\
unmarried & 0.086 & 0.281 & 0 & 26.23 \\
TLUs* & 4.990 & 3.669 & 0 & 2.912 \\
pc1 wealth ${ }^{* * *}$ & 0 & 1.214 & -3.415 & \\
**TLU stands for Tropical Livestock Units & \\
***Wealth is represented as the first principal component of several indicators
\end{tabular}

Rather than trying to obtain income measures - which would be unreliable in a sample consisting for the most part of subsistence farmers - we thus look at some variables likely to be closely associated with income. Table 2 summarizes the income proxies used, along with several other controls in the regression. The land size owned by our households ranges from 0 to 10.5 hectares, with a mean of 1.80. Notice how land size is indeed a proxy for income - and specifically not

\footnotetext{
${ }^{13}$ The parameter may also capture some systematic noise - as opposed to the truely random noise captured in $\sigma$ - consisting in answers that are systamatically closer to the midpoint of the choice list.
} 
a measure of wealth - in the present context, as it is illegal to buy or sell land in Ethiopia. While the use of land size as an income proxy clearly glosses over behavioral issues such as e.g. the use of fertilizer or effort expended on the farm, we consider this a strength of this measure, as it reduces the likelihood of causality running in the opposite direction. We do not have direct measures of income in our sample. However, using data collected in a representative survey run by the International Food Policy Research Institute (IFPRI), which is representative of an area largely overlapping with our study area in the Ethiopian highlands, land size and income show a clear positive correlation $(\rho=0.318, p<0.001, N=892$; Spearman rank correlation). This further confirms the validity of land size as an income proxy.

Our second income proxy is altitude. This measure is taken from GPS measurements, and measured as elevation above sea level. At between about 1450 and 3150 meters, the range of elevations in our data is significant. The productivity of land decreases with altitude for several reasons. Rainfall is generally scarcer at high altitudes. This effect is compounded by stronger winds, which tend to dry out the top soil. Furthermore, land at high altitude is often steeper, which means that water drains quickly and soil is easily eroded, leading to reduced soil quality and hence lower agricultural productivity. And finally, the lower temperatures prevalent at high altitudes lead to slower growth of crops. Recurring again to the same IFPRI data mentioned above, we indeed find a negative correlation between income and altitude $(\rho=-0.096, p=0.004, N=886)$. Nonetheless, altitude is clearly an imperfect proxy, as agricultural practices will also change with altitude. In particular, we find that at increasing altitudes land is increasingly used to graze livestock, i.e. there is a significant correlation between altitude and the tropical livestock units (TLUs) owned by a household in our data $(\rho=0.127, p=0.005, N=487)$. It is thus important to control for this in regression. There is no correlation between land size and altitude. ${ }^{14}$

\footnotetext{
${ }^{14}$ Altitude may, in principle, also have effects on the disease environment, with tropical temperatures at lower altitudes likely resulting in a higher prevalence of diseases such as malaria. Notice how this may reverse the effect we predict, as poor health is generally associated with reduced risk tolerance (Akay, Martinsson, Medhin and Trautmann, 2012). We do, however, not find a significant correlation between altitude and self-declared health state $(\rho=-0.014$,
} 
Table 3 shows our regression results. Regression I looks at proxies for income, while controlling for level of education, business ownership, and some demographics including the sex and age of the respondent, and his marital status. We find land size to be highly correlated with risk preferences, with larger land ownership being associated with higher risk tolerance as indicated by a smaller $\beta$ parameter, as we hypothesized. We also find higher altitudes to be related to reduced risk tolerance, again as hypothesized. Higher altitudes are also associated with increased probabilistic sensitivity. Adding an interaction term between land size and altitude (not shown) does not yield any additional insights. Regression II tests the stability of the findings by adding indicators of wealth. In particular, we add tropical livestock units owned. This is important inasmuch as farmers at higher altitudes increasingly switch to livestock. In addition, we add the first principal component of wealth constructed out of a number of wealth indicators (Filmer and Pritchett, 2001), such as number of houses owned, number of rooms, whether the house has a water closet, materials of roof and wall, and whether the household has a private telephone. Adding these variables does not yield additional insights. Importantly, the effects of altitude (as well as land size) remain significant.

We also find some effect for the demographic controls. Most notably, we find unmarried subjects, which make up about $9 \%$ of the sample, to be less risk averse, and older and female subjects to be more risk averse. These effects correspond to the majority of results in the literature, although not all of them are uncontroversial. For instance, while gender effects have often been found (Croson and Gneezy, 2009), they may be sensitive to the elicitation task and decision context (Filippin and Crosetto, 2015), as well as socialization (Booth and Nolen, 2012). Notice, however, that females in our sample are female household heads. Female-headed households are also likely to be poorer than male-headed households on average and particularly vulnerable, which may partially explain the strength of the gender effect we find (see also footnote 3 ).

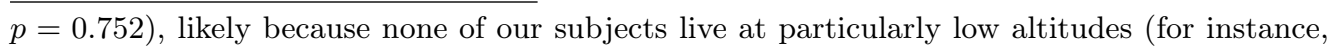
malaria is virtually inexistent in the Ethiopian highlands). Since we did not find a direct effect of health on risk preferences either, we will not further mention this variable. 
Table 3: Income and wealth

\begin{tabular}{|c|c|c|c|c|c|c|}
\hline & \multicolumn{3}{|c|}{ I } & \multicolumn{3}{|c|}{ II } \\
\hline & $\alpha$ & $\beta$ & $\sigma$ & $\alpha$ & $\beta$ & $\sigma$ \\
\hline land size & $\begin{array}{l}-0.015 \\
(0.017)\end{array}$ & $\begin{array}{c}-0.057^{* * *} \\
(0.020)\end{array}$ & $\begin{array}{c}0.003 \\
(0.008)\end{array}$ & $\begin{array}{l}-0.006 \\
(0.019)\end{array}$ & $\begin{array}{c}-0.054^{* *} \\
(0.024)\end{array}$ & $\begin{array}{c}0.002 \\
(0.008)\end{array}$ \\
\hline altitude & $\begin{array}{c}0.046^{* * *} \\
(0.015)\end{array}$ & $\begin{array}{c}0.085^{* * *} \\
(0.024)\end{array}$ & $\begin{array}{c}-0.036^{* * *} \\
(0.005)\end{array}$ & $\begin{array}{c}0.040^{* *} \\
(0.017)\end{array}$ & $\begin{array}{c}0.087^{* * *} \\
(0.028)\end{array}$ & $\begin{array}{c}-0.035^{* * *} \\
(0.006)\end{array}$ \\
\hline literate & $\begin{array}{c}0.012 \\
(0.034)\end{array}$ & $\begin{array}{c}0.060 \\
(0.045)\end{array}$ & $\begin{array}{c}0.005 \\
(0.013)\end{array}$ & $\begin{array}{l}-0.001 \\
(0.035)\end{array}$ & $\begin{array}{c}0.062 \\
(0.046)\end{array}$ & $\begin{array}{c}0.004 \\
(0.013)\end{array}$ \\
\hline middle school & $\begin{array}{c}0.048 \\
(0.053)\end{array}$ & $\begin{array}{l}0.116^{*} \\
(0.070)\end{array}$ & $\begin{array}{l}-0.001 \\
(0.018)\end{array}$ & $\begin{array}{c}0.035 \\
(0.052)\end{array}$ & $\begin{array}{l}0.117^{*} \\
(0.071)\end{array}$ & $\begin{array}{c}0.002 \\
(0.019)\end{array}$ \\
\hline business & $\begin{array}{l}-0.038 \\
(0.098)\end{array}$ & $\begin{array}{c}0.079 \\
(0.143)\end{array}$ & $\begin{array}{l}-0.038 \\
(0.052)\end{array}$ & $\begin{array}{c}0.064 \\
(0.114)\end{array}$ & $\begin{array}{c}0.038 \\
(0.165)\end{array}$ & $\begin{array}{l}-0.049 \\
(0.061)\end{array}$ \\
\hline female & $\begin{array}{l}-0.110 \\
(0.067)\end{array}$ & $\begin{array}{c}0.207^{* *} \\
(0.089)\end{array}$ & $\begin{array}{c}0.029 \\
(0.028)\end{array}$ & $\begin{array}{l}-0.106 \\
(0.071)\end{array}$ & $\begin{array}{c}0.204^{* *} \\
(0.091)\end{array}$ & $\begin{array}{c}0.028 \\
(0.028)\end{array}$ \\
\hline age & $\begin{array}{l}-0.006 \\
(0.018)\end{array}$ & $\begin{array}{c}0.050^{* *} \\
(0.020)\end{array}$ & $\begin{array}{c}-0.014^{* * *} \\
(0.005)\end{array}$ & $\begin{array}{l}-0.009 \\
(0.018)\end{array}$ & $\begin{array}{c}0.047^{* *} \\
(0.021)\end{array}$ & $\begin{array}{c}-0.015^{* * *} \\
(0.006)\end{array}$ \\
\hline unmarried & $\begin{array}{c}0.029 \\
(0.075) \\
(0.058)\end{array}$ & $\begin{array}{c}-0.193^{* *} \\
(0.083) \\
(0.069)\end{array}$ & $\begin{array}{l}-0.013 \\
(0.021) \\
(0.018)\end{array}$ & $\begin{array}{c}0.001 \\
(0.075) \\
(0.059)\end{array}$ & $\begin{array}{c}-0.186^{* *} \\
(0.087) \\
(0.071)\end{array}$ & $\begin{array}{l}-0.012 \\
(0.021) \\
(0.018)\end{array}$ \\
\hline TLUs & & & & $\begin{array}{c}-0.000 \\
(0.017)\end{array}$ & $\begin{array}{l}-0.005 \\
(0.022)\end{array}$ & $\begin{array}{l}-0.003 \\
(0.006)\end{array}$ \\
\hline wealth pc1 & & & & $\begin{array}{l}-0.017 \\
(0.015)\end{array}$ & $\begin{array}{l}-0.003 \\
(0.015)\end{array}$ & $\begin{array}{c}0.006 \\
(0.006)\end{array}$ \\
\hline Region dummies & $\checkmark$ & $\checkmark$ & $\checkmark$ & $\checkmark$ & $\checkmark$ & $\checkmark$ \\
\hline constant & $\begin{array}{c}0.675^{* * *} \\
(0.040)\end{array}$ & $\begin{array}{c}0.637^{* * *} \\
(0.039)\end{array}$ & $\begin{array}{c}0.181^{* * *} \\
(0.013)\end{array}$ & $\begin{array}{c}0.689^{* * *} \\
(0.043)\end{array}$ & $\begin{array}{c}0.636^{* * *} \\
(0.041)\end{array}$ & $\begin{array}{c}0.178^{* * *} \\
(0.014)\end{array}$ \\
\hline Subjects & 493 & 493 & 493 & 486 & 486 & 486 \\
\hline$L L$ & $-12,335.17$ & $-12,335.17$ & $-12,335.17$ & $-12,163.75$ & $-12,163.75$ & $-12,163.75$ \\
\hline
\end{tabular}

There is little evidence to date on the direction of causality in the correlation between risk aversion and income. ${ }^{15}$ Gloede et al. (2013) showed that risk preferences in Thailand and Vietnam are influenced by several types of shocks using experimentally validated survey questions (Hardeweg, Menkhoff and Waibel, 2013), but it is unclear whether the effect of these shocks passes purely through income or whether they have a direct, possibly psychological, effect on risk preferences. Tanaka et al. (2010) used an instrumental variables approach, but did so only for the utility curvature parameter, for which they did not find a significant effect of income in the first place. ${ }^{16}$

\footnotetext{
${ }^{15}$ Guiso and Paiella (2008) found an effect of windfalls in wealth on a hypothetical question about finacial investment. Since financial investments are strongly dependent on wealth levels in the first place, however, it is unclear whether this is a true effect on preferences.

${ }^{16}$ To be precise, they did not find a significant effect of either personal or average village income on utility curvature in the OLS regressions. They found a marginally significant effect of mean village income (but not of personal income) in the 2SLS regression, but did not discuss the possibility of a direct effect of their instruments on risk preferences. No IV regression is
} 
Given that there is little migration in Ethiopia (Di Falco and Bulte, 2013), the altitude at which a family lives can plausibly be taken as exogenous. This means that the effect of altitude detected in the regression above can be interpreted as causal. For land size, the story is more complicated, as the legitimacy of any causal interpretation will depend on how the land has been acquired, and whether risk preferences may have influenced this acquisition. Table 4 replicates regression I above, but restricts the sample to the roughly $52 \%$ of subjects who declare to have inherited their land from their parents (as opposed to having obtained it through land redistribution, $44 \%$, or through other means $3 \%){ }^{17}$ Restricting the sample in this way serves again to establish exogeneity of the variable, since the size of the land owned in this case has not been influenced by the household head. ${ }^{18}$ If anything, the correlation between land size and risk tolerance is stronger in this sub-sample, suggesting indeed a causal relation running from income to risk tolerance. Once again, the causal relationship can only be plausibly established. Indeed for land size, we cannot completely exclude other explanations based on parents passing on their risk preference together with the land. Given relatively low intergenerational correlation coefficients of risk preferences, however, we find such an alternative account to be much less plausible than the one presented here.

\subsection{Stability analysis}

In this section, we replicate the main findings from above using non-parametric data. While non-parametric analysis will likely result in weakened results due

reported for the loss aversion coefficient, which shows a negative correlation with mean village income (but not personal income) in the OLS regressions.

${ }^{17}$ Since 1975, all land in Ethiopia is public property. There used to be land redistribution at the village levels through the 1990s by local committees. While family size was supposed to be the main criterion, it is suspected that corruption strongly influenced redistribution decisions. Since the 1990's, land certification and registration has started, giving farmers permanent title to the land. Given the role of family size and corruption in land redistribution, we cannot be assured of the exogneity of land allocations. If we nontheless only use the subsample that has obtained the land by redistribution, we again find a significant effect of land size on risk tolerance.

${ }^{18}$ Altitude no longer has a significant effect on average risk preferences, captured by $\beta$, in this subsample. Notice however that altitude is likely exogneous in the whole sample, so that the loss of significance in this subsample is of little concern. 
Table 4: Income and wealth

\begin{tabular}{lccc}
\hline & $\alpha$ & $\beta$ & $\sigma$ \\
\hline land size & $-0.065^{* *}$ & $-0.062^{* * *}$ & 0.011 \\
altitude & $(0.029)$ & $(0.023)$ & $(0.014)$ \\
& $0.071^{* * *}$ & 0.029 & $-0.023^{* *}$ \\
literate & $(0.027)$ & $(0.031)$ & $(0.011)$ \\
& -0.010 & $0.103^{*}$ & 0.028 \\
middle school & $(0.050)$ & $(0.055)$ & $(0.018)$ \\
& 0.087 & $0.150^{*}$ & -0.006 \\
business & $(0.079)$ & $(0.081)$ & $(0.020)$ \\
female & -0.156 & 0.172 & -0.008 \\
& $(0.096)$ & $(0.165)$ & $(0.063)$ \\
age & -0.090 & $0.180^{* *}$ & -0.035 \\
& $(0.070)$ & $(0.084)$ & $(0.022)$ \\
unmarried & -0.013 & $0.100^{* * *}$ & -0.013 \\
& $(0.032)$ & $(0.035)$ & $(0.010)$ \\
Region dummies & 0.068 & $-0.311^{* * *}$ & 0.051 \\
constant & $(0.121)$ & $(0.093)$ & $(0.039)$ \\
& $\checkmark$ & $\checkmark$ & $\checkmark$ \\
\hline Subjects & $0.675^{* * *}$ & $0.641^{* * *}$ & $0.120^{* * *}$ \\
$L L$ & $(0.071)$ & $(0.071)$ & $(0.016)$ \\
\hline SEs in parentheses; ${ }^{*} \mathrm{p}<0.1, * * \mathrm{p}<0.05, * * * \mathrm{p}<0.01$ \\
Continuous independent variables entered as z-scores
\end{tabular}

to the noise incorporated in the measures, this is nevertheless useful in order to establish the stability of our main findings. Table 5 shows the three regressions from the two tables in the previous section, using OLS with robust standard errors. The dependent variable is now simply constructed as the average certainty equivalent per person. ${ }^{19}$ Regression I shows that land size still shows the expected effect, with larger land holdings being correlated with larger certainty equivalents on average, and thus increased risk tolerance. Altitude shows a significant effect in the opposite direction, again as seen previously. Regression II adds the first principal component of wealth and tropical livestock units. None of these wealth indicators are significant, while altitude remains highly significant. Land size also remains significant, but only at the $10 \%$ level. The lower significance is likely due to the collinearity with tropical livestock units, and is of little import here, since the controls were mostly inserted to test the stability of the altitude variable.

Finally, regression III uses only the restricted sample of households having

\footnotetext{
${ }^{19}$ Alternatively, we could use a panel data approach and enter the probability as an independent variable. This yields the same results, so that we prefer to report this simpler version of the regression.
} 
Table 5: Nonparametric stability analysis

\begin{tabular}{|c|c|c|c|}
\hline dep. var.: mean $(\mathrm{CE})$ & I & II & III \\
\hline land size & $\begin{array}{c}0.891^{* * *} \\
(0.344)\end{array}$ & $\begin{array}{l}0.798^{*} \\
(0.413)\end{array}$ & $\begin{array}{l}0.836^{*} \\
(0.489)\end{array}$ \\
\hline altitude & $\begin{array}{c}-1.096^{* * *} \\
(0.356)\end{array}$ & $\begin{array}{c}-1.108^{* * *} \\
(0.413)\end{array}$ & $\begin{array}{l}-0.489 \\
(0.475)\end{array}$ \\
\hline literate & $\begin{array}{l}-1.093 \\
(0.761)\end{array}$ & $\begin{array}{l}-1.256 \\
(0.776)\end{array}$ & $\begin{array}{l}-1.624 \\
(1.105)\end{array}$ \\
\hline middle school & $\begin{array}{l}-1.955^{*} \\
(1.148)\end{array}$ & $\begin{array}{l}-2.073^{*} \\
(1.167)\end{array}$ & $\begin{array}{l}-1.706 \\
(1.371)\end{array}$ \\
\hline business & $\begin{array}{l}-0.922 \\
(2.154)\end{array}$ & $\begin{array}{c}0.336 \\
(2.380)\end{array}$ & $\begin{array}{l}-1.777 \\
(3.060)\end{array}$ \\
\hline female & $\begin{array}{c}-3.302^{* *} \\
(1.498)\end{array}$ & $\begin{array}{c}-3.298^{* *} \\
(1.526)\end{array}$ & $\begin{array}{l}-3.217^{*} \\
(1.905)\end{array}$ \\
\hline age & $\begin{array}{c}-0.868^{* *} \\
(0.360)\end{array}$ & $\begin{array}{c}-0.895^{* *} \\
(0.367)\end{array}$ & $\begin{array}{c}-1.780^{* * *} \\
(0.577)\end{array}$ \\
\hline unmarried & $\begin{array}{l}2.743^{*} \\
(1.472)\end{array}$ & $\begin{array}{l}2.714^{*} \\
(1.520)\end{array}$ & $\begin{array}{c}5.747^{* * *} \\
(2.031)\end{array}$ \\
\hline TLUs & & $\begin{array}{c}0.113 \\
(0.416)\end{array}$ & \\
\hline pc1 & & $\begin{array}{c}0.139 \\
(0.279)\end{array}$ & \\
\hline Region fixed effects & $\checkmark$ & $\checkmark$ & $\checkmark$ \\
\hline constant & $\begin{array}{c}24.266^{* * *} \\
(0.725)\end{array}$ & $\begin{array}{c}24.295^{* * *} \\
(0.785)\end{array}$ & $\begin{array}{c}23.479^{* * *} \\
(0.847)\end{array}$ \\
\hline Subjects & 493 & 486 & 252 \\
\hline$R^{2}$ & 0.06 & 0.06 & 0.07 \\
\hline
\end{tabular}

inherited their land. Again, we can replicate most of the effects found previously. The effect of land size, however, is only marginally significant in this setting. Altitude is no longer significant, but this is of little consequence, as altitudes is plausibly exogenous for the whole sample.

\section{Discussion and conclusion}

We have examined the risk preferences of rural Ethiopian households using certainty equivalents. The results expand and generalize recent findings according to which students in poor countries are on average more risk tolerant than students in rich, industrialized, countries. In particular, the finding of high levels of risk tolerance in one of the poorest countries in the world indicates that the differences found in the student comparison are not merely due to systematic selection effects of relatively richer students in poorer countries, but that this 
result indicates a more general phenomenon. The negative correlation between risk tolerance and GDP found in the between country data contrasts markedly with the prevalent within-country evidence. Here we find a positive correlation of risk tolerance with income proxies, in agreement with a large (if not always consistent) body of evidence from industrialized countries (Dohmen et al., 2011; Donkers et al., 2001; Hopland et al., 2013). These opposing effects of national income between countries and personal income within countries gives rise to a risk-income paradox.

Vieider et al. (2012) explain this paradox recurring to unified growth theory, and in particular the hypothesis developed by Galor and Michalopoulos (2012). In poor societies that find themselves in a Malthusian equilibrium, relatively affluent, risk tolerant people have the largest number of children. Since risk preferences are transmitted within the family, risk tolerance spreads in the population. As societies grow richer, however, the affluent are the first to substitute quality for quantity of children (Becker, Murphy and Tamura, 1990). As more affluent families decrease the number of children, poorer families at first increase them, since the income constraint is no longer binding. This in turn leads to an inversion of the equilibrium and the spread of risk aversion.

Most evidence on risk preferences in developing countries stems from studies using a single choice list (Binswanger, 1980; Yesuf and Bluffstone, 2009). Responses to such a list may, however, be contaminated by noise. One of the presumed virtues of the Binswanger list is that it does not allow for any noise to register in the response, given that subjects are asked to pick their favorite amongst a list of lotteries. This, however, makes it impossible to tease apart econometrically how much noise played into the response, and in general preference data and noise can thus not be separately identified. Andersson et al. (2015) showed how noise may systematically be counted towards risk aversion in some choice list designs, thus resulting in spurious correlations. This criticism particularly applies to the Binswanger design - given that the choice list is capped at risk neutrality, random choices will be systematically counted towards risk aversion. A curious outlier in this respect is Akay et al. (2012), who found 
high levels of risk aversion eliciting CEs with poor farmers in Ethiopia. The latter finding appears to be driven mostly by subjects who consistently chose the sure amount for all choices. Since the design did not include the lower outcome of the prospect, however, it is hard to tell whether this behaviour reflects true preferences, or whether it is driven by misunderstanding the task.

The findings of considerable risk tolerance by our subjects raises the question what may be driving the reluctance to adopt new technologies that has often been observed in developing countries, and which has frequently been attributed to risk aversion. In the face of this evidence, such a conclusion does not appear to be tenable - at least not in any simple sense. One possible alternative explanation is that reluctance to switch to new technologies may be driven by downward risk exposure - the extend to which basic consumption needed for survival would suffer in the case of an adverse shock (Dercon and Christiaensen, 2011). Other explanations obviously exist as well, including low trust in the information provided by outsiders, slow information diffusion through social networks, etc. This is an important question raised by our data, the investigation of which will hopefully shed some fresh light on what induces people to take risks in real life decisions beyond their pure risk preferences as measured in economic experiments.

Risk preferences have often been shown to correlate with income (Dohmen et al., 2011; Hopland et al., 2013; Vieider et al., 2013). At the same time, parts of the literature have examined the correlation of risk preferences with behavior (e.g., Liu, 2013). An element that most of these studies have in common is that the direction of causality was either bypassed by assuming innate preferences, or that only correlation results were presented. In the present study, we took a step in the direction of formally addressing causality by using exogenous proxies for income. While this showed that some of the causality seems to run from income to risk tolerance, this does not exclude the opposite direction of causality, since we cannot exactly quantify the effect in our reduced from regressions.

Although not being the main point of our analysis, our results have shown that both allowing for a stochastic structure and choosing a flexible enough model to fit the data well may be important for correlation analysis. Clearly, our pre- 
liminary insights into this issue are not conclusive, and more research is needed to determine the generality of this finding. An additional methodological point is that certainty equivalents, so far rarely used in development economics but a standard tool in decision theory, hold great promise for the application with poor and often illiterate subjects. Comparing different sure amounts of money to a prospect with a constant probability is easy to explain and represent physically, and appears to produce good results. In this paper, we have concentrated on eliciting such certainty equivalents for pure gain prospects. Indeed, they provide the cleanest test for our hypotheses, as one need not worry about giving subjects endowments from which losses are deducted as in pure loss or mixed prospects, and about whether subject integrate these endowments into their decisions or not. Nonetheless, the method is easily extendable to pure loss and mixed prospects if the research questions makes this desirable, as is the case if one wants to find correlations with many real world decisions. 


\section{A Results using 1-parameter EU}

In the present section, we estimate the same regressions as in the main text using an expected utility framework with a power utility formulation. This will leave our econometric apparatus above intact, except that our predicted certainty equivalent now takes the following form:

$$
\hat{c} e_{i}=u^{-1}\left[p_{i} u(x)+\left(1-p_{i}\right) u(y)\right]=u^{-1}\left[p_{i} u(x)\right]
$$

where utility takes the form $u(x)=x^{\rho}$ (alternative functional forms produce similar results). The fit of the resulting function to the nonparametric data is shown in figure 3. As already discussed above, this one-parameter function does not provide a good fit on average, as it cannot account for both risk seeking and risk aversion. Rather, it reflects the average pattern of risk seeking, resulting in a parameter estimate of $\rho=1.634(s e=0.065)$, and thus a globally convex utility function.

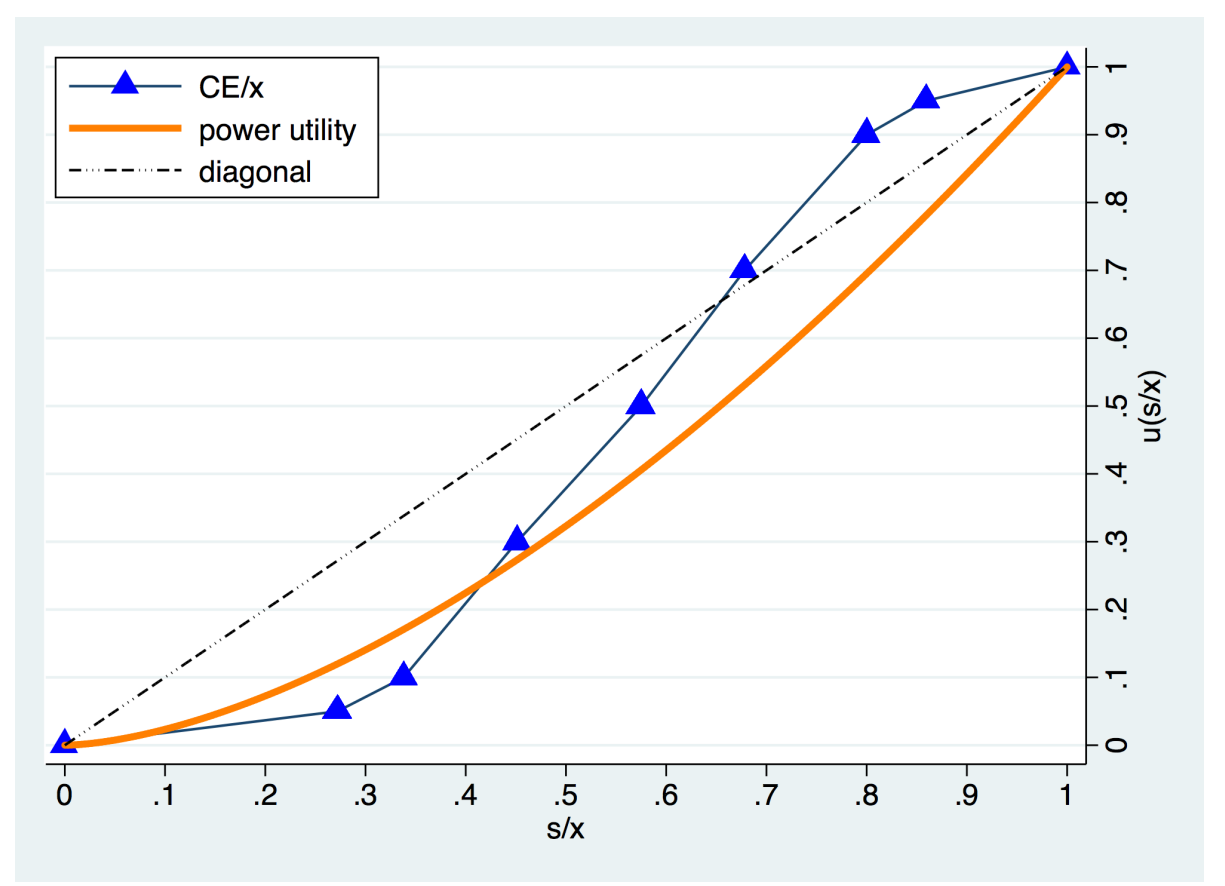

Figure 3: Fitting 2-parameter functions to the data

Table 6 shows the same four regressions as above using the expected utility formulation. Both land size and altitude have the expected significant effects 
in regression I. In regression II, land size has an even higher coefficient and is marginally significant. While the structural modeling improves our correlations somewhat relative to the non-parametric measures, several effects that were significant with the 2-parameter model are not picked up. This is likely due to the bad fit of the 1-parameter model. The complex patterns of risk seeking combined with risk aversion visible from the nonparametric data points cannot be accommodated by such a function. This, in turn, means that error rates will be larger. And indeed we can see that the standard errors in the expected utility model are considerably larger than the ones seen in the dual model presented above.

Table 6: Stability analysis EU

\begin{tabular}{|c|c|c|c|c|}
\hline & \multicolumn{2}{|c|}{ I } & \multicolumn{2}{|c|}{ II } \\
\hline & $\rho$ & $\sigma$ & $\rho$ & $\sigma$ \\
\hline land size & $\begin{array}{c}0.186^{* * *} \\
(0.066)\end{array}$ & $\begin{array}{c}0.007 \\
(0.009)\end{array}$ & $\begin{array}{c}0.293^{*} \\
(0.156)\end{array}$ & $\begin{array}{c}0.032^{*} \\
(0.019)\end{array}$ \\
\hline distance road & $\begin{array}{c}0.054 \\
(0.081)\end{array}$ & $\begin{array}{c}0.003 \\
(0.009)\end{array}$ & $\begin{array}{c}0.119 \\
(0.132)\end{array}$ & $\begin{array}{c}0.004 \\
(0.014)\end{array}$ \\
\hline altitude & $\begin{array}{c}-0.280^{* * *} \\
(0.076)\end{array}$ & $\begin{array}{c}-0.036^{* * *} \\
(0.007)\end{array}$ & $\begin{array}{l}-0.134 \\
(0.137)\end{array}$ & $\begin{array}{l}-0.019 \\
(0.018)\end{array}$ \\
\hline literate & $\begin{array}{l}-0.159 \\
(0.104)\end{array}$ & $\begin{array}{c}0.002 \\
(0.015)\end{array}$ & $\begin{array}{c}-0.216 \\
(0.150)\end{array}$ & $\begin{array}{c}0.025 \\
(0.020)\end{array}$ \\
\hline middle school & $\begin{array}{l}-0.250 \\
(0.222)\end{array}$ & $\begin{array}{l}-0.005 \\
(0.020)\end{array}$ & $\begin{array}{l}-0.389 \\
(0.244)\end{array}$ & $\begin{array}{l}-0.029 \\
(0.026)\end{array}$ \\
\hline business & $\begin{array}{l}-0.366 \\
(0.309)\end{array}$ & $\begin{array}{l}-0.030 \\
(0.054)\end{array}$ & $\begin{array}{l}-0.429 \\
(0.446)\end{array}$ & $\begin{array}{c}0.021 \\
(0.063)\end{array}$ \\
\hline female & $\begin{array}{c}-0.329^{*} \\
(0.188)\end{array}$ & $\begin{array}{c}0.040 \\
(0.029)\end{array}$ & $\begin{array}{l}-0.293 \\
(0.254)\end{array}$ & $\begin{array}{c}0.001 \\
(0.029)\end{array}$ \\
\hline age & $\begin{array}{c}-0.179^{* * *} \\
(0.048)\end{array}$ & $\begin{array}{c}-0.012^{*} \\
(0.007)\end{array}$ & $\begin{array}{c}-0.290^{* * *} \\
(0.074)\end{array}$ & $\begin{array}{l}-0.017 \\
(0.012)\end{array}$ \\
\hline unmarried & $\begin{array}{c}0.446^{* *} \\
(0.185)\end{array}$ & $\begin{array}{c}-0.003 \\
(0.024)\end{array}$ & $\begin{array}{c}1.027^{* *} \\
(0.450)\end{array}$ & $\begin{array}{c}0.043 \\
(0.045)\end{array}$ \\
\hline region fixed effects & $\checkmark$ & $\checkmark$ & $\checkmark$ & $\checkmark$ \\
\hline constant & $\begin{array}{c}1.830^{* * *} \\
(0.117)\end{array}$ & $\begin{array}{c}0.193^{* * *} \\
(0.015)\end{array}$ & $\begin{array}{c}1.915^{* * *} \\
(0.252)\end{array}$ & $\begin{array}{c}0.143^{* * *} \\
(0.022)\end{array}$ \\
\hline $\begin{array}{l}\mathrm{N}_{\text {chi2 }} \text { clust } \\
\text { che }\end{array}$ & $\begin{array}{c}493 \\
45.85\end{array}$ & & $\begin{array}{c}254 \\
49.57\end{array}$ & \\
\hline
\end{tabular}




\section{References}

Abdellaoui, Mohammed (2000) 'Parameter-Free Elicitation of Utility and Probability Weighting Functions.' Management Science 46(11), 1497-1512

Abdellaoui, Mohammed, Aurélien Baillon, Lætitia Placido, and Peter P. Wakker (2011) 'The Rich Domain of Uncertainty : Source Functions and Their Experimental Implementation.' American Economic Review 101, 695-723

Akay, Alpaslan, Peter Martinsson, Haileselassie Medhin, and Stefan Trautmann (2012) 'Attitudes toward uncertainty among the poor: an experiment in rural Ethiopia.' Theory and Decision 73(3), 453-464

Andersen, Steffen, Glenn W. Harrison, Morten Igel Lau, and E. Elisabet Rutström (2010) 'Preference heterogeneity in experiments: Comparing the field and laboratory.' Journal of Economic Behavior \& Organization 73(2), 209-224

Andersson, Ola, Jean-Robert Tyran, Erik Wengström, and Håkan J. Holm (2015) 'Risk Aversion Relates to Cognitive Ability: Preferences or Noise?' Journal of the European Economic Association, forthcoming

Apesteguia, José, and Miguel A. Ballester (2014) 'Discrete choice estimation of risk aversion.' Working Paper

Arrow, Kenneth J (1970) Essays in the Theory of Risk-Bearing (Amsterdam)

Attanasio, Orazio, Abigail Barr, Juan Camilo Cardenas, Garance Genicot, and Costas Meghir (2012) 'Risk Pooling, Risk Preferences, and Social Networ.' American Economic Journal: Applied Economics 4(2), 134-167

Bacon, Philomena M., Anna Conte, and Peter G. Moffatt (2014) 'Assortative mating on risk attitude.' Theory and Decision 77(3), 389-401

Becker, Gary S., Kevin M. Murphy, and Robert Tamura (1990) 'Human Capital, Fertility, and Economic Growth.' Journal of Political Economy 98(5), S12-S37

Binswanger, Hans P. (1980) 'Attitudes toward Risk: Experimental Measurement in Rural India.' American Journal of Agricultural Economics 62(3), 395-407 
Bleichrodt, Han, and Jose Luis Pinto (2000) 'A Parameter-Free Elicitation of the Probability Weighting Function in Medical Decision Analysis.' Management Science 46(11), 1485-1496

Booij, Adam S., Bernard M. S. van Praag, and Gijs van de Kuilen (2010) 'A parametric analysis of prospect theory's functionals for the general population.' Theory and Decision 68(1-2), 115-148

Booth, Alison L., and Patrick Nolen (2012) 'Gender differences in risk behaviour: does nurture matter?*'. The Economic Journal 122(558), F56-F78

Bruhin, Adrian, Helga Fehr-Duda, and Thomas Epper (2010) 'Risk and Rationality: Uncovering Heterogeneity in Probability Distortion.' Econometrica 78(4), 1375-1412

Cardenas, Juan Camilo, and Jeffrey Carpenter (2013) 'Risk attitudes and economic well-being in Latin America.' Journal of Development Economics $103,52-61$

Charness, Gary, and Angelino Viceisza (2012) 'Comprehension and Risk Elicitation in the Field: Evidence from Rural Senegal.' working paper

Crosetto, Paolo, and Antonio Filippin (2015) 'A theoretical and experimental appraisal of four risk elicitation methods.' Experimental Economics pp. 1-29

Croson, Rachel, and Uri Gneezy (2009) 'Gender Differences in Preferences.' Journal of Economic Literature 47(2), 1-27

Cubitt, Robin P., Chris Starmer, and Robert Sugden (1998) 'On the Validity of Random Lottery Incentive Systems.' Experimental Economics 1, 115-131

Dercon, Stefan, and Luc Christiaensen (2011) 'Consumption risk, technology adoption and poverty traps: Evidence from Ethiopia.' Journal of Development Economics 96(2), 159-173

Di Falco, Salvatore, and Erwin Bulte (2013) 'The Impact of Kinship Networks on 
the Adoption of Risk-Mitigating Strategies in Ethiopia.' World Development 43, 100-110

Di Falco, Salvatore, and Ferdinand M. Vieider (2015) 'Risk preferences, sex, and cultural assimilation: Evidence from a representative sample of Ethiopian highlanders.' Working Paper

Diecidue, Enrico, and Jeroen van de Ven (2008) 'Aspiration Level, Probability of Success and Failure, and Expected Utility.' International Economic Review $49(2), 683-700$

Dohmen, Thomas, Armin Falk, David Huffman, Uwe Sunde, Jürgen Schupp, and Gert G. Wagner (2011) 'Individual Risk Attitudes: Measurement, Determinants, and Behavioral Consequences.' Journal of the European Economic Association 9(3), 522-550

Donkers, Bas, Bertrand Melenberg, and Arthur Van Soest (2001) 'Estimating Risk Attitudes Using Lotteries: A Large Sample Approach.' Journal of Risk and Uncertainty 22(2), $165-95$

Fehr-Duda, Helga, and Thomas Epper (2012) 'Probability and Risk: Foundations and Economic Implications of Probability-Dependent Risk Preferences.' Annual Review of Economics 4(1), 567-593

Filippin, Antonio, and Paolo Crosetto (2015) 'A Reconsideration of Gender Differences in Risk Attitudes.' Management Science, forthcoming

Filmer, Deon, and Lant H. Pritchett (2001) 'Estimating Wealth Effects Without Expenditure Data - Or Tears: An Application To Educational Enrollments In States Of India*.' Demography 38(1), 115-132

Galor, Oded, and Stelios Michalopoulos (2012) 'Evolution and the Growth Process: Natural Selection of Entrepreneurial Traits.' Journal of Economic Theory $147(2), 759-780$ 
Gloede, Oliver, Lukas Menkhoff, and Hermann Waibel (2013) 'Shocks, Individual Risk Attitude, and Vulnerability to Poverty among Rural Households in Thailand and Vietnam.' World Development, forthcoming

Gollier, Christian, and John W. Pratt (1996) 'Risk Vulnerability and the Tempering Effect of Background Risk.' Econometrica 64(5), 1109

Guiso, Luigi, and Monica Paiella (2008) 'Risk Aversion, Wealth, and Background Risk.' Journal of the European Economic Association 6(6), 1109-1150

Hardeweg, Bernd, Lukas Menkhoff, and Hermann Waibel (2013) 'Experimentally Validated Survey Evidence on Individual Risk Attitudes in Rural Thailand.' Economic Development and Cultural Change 61(4), 859-888

Harrison, Glenn W., Morten I. Lau, and Elizabeth E. Rutström (2007) 'Estimating Risk Attitudes in Denmark: A Field Experiment.' Scandinavian Journal of Economics 109, 341-368

Harrison, Glenn W., Steven J. Humphrey, and Arjan Verschoor (2010) 'Choice under Uncertainty: Evidence from Ethiopia, India and Uganda.' Economic Journal 120(543), 80-104

Haushofer, Johannes, and Ernst Fehr (2014) 'On the psychology of poverty.' Science 344(6186), 862-867

Holt, Charles A., and Susan K. Laury (2002) 'Risk Aversion and Incentive Effects.' American Economic Review 92(5), 1644-1655

Hopland, Arnt O., Egil Matsen, and Bjarne Strøm (2013) 'Income and choice under risk.' Working Paper Series 14313, Department of Economics, Norwegian University of Science and Technology

Kahneman, Daniel, and Amos Tversky (1979) 'Prospect Theory: An Analysis of Decision under Risk.' Econometrica 47(2), 263 - 291

Kőszegi, Botond, and Matthew Rabin (2007) 'Reference-Dependent Risk Attitudes.' The American Economic Review 97(4), 1047-1073 
L'Haridon, Olivier, and Ferdinand M. Vieider (2015) 'All over the map: Heterogeneity of risk preferences across individuals, contexts, and countries.' Working paper

Liebenehm, Sabine, and Hermann Waibel (2014) 'Simultaneous estimation of risk and time preferences among small-scale farmers in West Africa.' American Journal of Agricultural Economics, forthcoming

Liu, Elaine M. (2013) 'Risk Preferences and Technology Adoption Decisions of Cotton Farmers in China.' working paper

Lönnqvist, Jan-Erik, Marrku Verkasalo, Gari Walkowitz, and Philipp C. Wichardt (2011) 'Measuring Individual Risk Attitudes in the Lab: Task or Ask? An Empirical Comparison.' Working Paper

Markowitz, Harry (1952) 'The Utility of Wealth.' Journal of Political Economy $60(2), 151-158$

Noussair, Charles N., Stefan Trautmann, and Gijs van de Kuilen (2014) 'Higher Order Risk Attitudes, Demographics, and Financial Decisions.' Review of Economic Studies 21(1), 325-355

Prelec, Drazen (1998) 'The Probability Weighting Function.' Econometrica $66,497-527$

Preston, Malcolm G., and Philip Baratta (1948) 'An experimental study of the auction-value of an uncertain outcome.' The American Journal of Psychology $61,183-193$

Rieger, Marc Oliver, Mei Wang, and Thorsten Hens (2014) 'Risk Preferences Around the World.' Management Science 61(3), 637 - 648

Sugden, Robert (2003) 'Reference-dependent subjective expected utility.' Journal of Economic Theory 111(2), 172-191

Tanaka, Tomomi, Colin F. Camerer, and Quang Nguyen (2010) 'Risk and Time 
Preferences: Linking Experimental and Household Survey Data from Vietnam.' American Economic Review 100(1), 557-571

Tversky, Amos, and Daniel Kahneman (1992) 'Advances in Prospect Theory: Cumulative Representation of Uncertainty.' Journal of Risk and Uncertainty $5,297-323$

Tversky, Amos, and Peter P. Wakker (1995) 'Risk Attitudes and Decision Weights.' Econometrica 63(6), 1255-1280

Vieider, Ferdinand M., Mathieu Lefebvre, Ranoua Bouchouicha, Thorsten Chmura, Rustamdjan Hakimov, Michal Krawczyk, and Peter Martinsson (2015) 'Common components of risk and uncertainty attitudes across contexts and domains: Evidence from 30 countries.' Journal of the European Economic Association 13(3), 421-452

Vieider, Ferdinand M., Nghi Truong, Peter Martinsson, and Nam Pham Khanh (2013) 'Risk Preferences and Development Revisited.' WZB Discussion Paper SP II 2013-403

Vieider, Ferdinand M., Thorsten Chmura, and Peter Martinsson (2012) 'Risk Attitudes, Development, and Growth. Macroeconomic Evidence from Experiments in 30 Countries.' WZB Working paper

von Gaudecker, Hans-Martin, Arthur van Soest, and Erik Wengström (2011)

'Heterogeneity in Risky Choice Behaviour in a Broad Population.' American Economic Review 101(2), 664-694

Wakker, Peter P. (2010) Prospect Theory for Risk and Ambiguity (Cambridge: Cambridge University Press)

Wilcox, Nathaniel T. (2011) “Stochastically more risk averse:' A contextual theory of stochastic discrete choice under risk.' Journal of Econometrics 162(1), 89-104

Wu, George, and Richard Gonzalez (1996) 'Curvature of the Probability Weighting Function.' Management Science 42(12), 1676-1690 
Yaari, Menahem E. (1987) 'The Dual Theory of Choice under Risk.' Econometrica $55(1), 95-115$

Yesuf, Mahmud, and Randall A. Bluffstone (2009) 'Poverty, Risk Aversion, and Path Dependence in Low-Income Countries: Experimental Evidence from Ethiopia.' American Journal of Agricultural Economics 91(4), 1022-1037

Zilibotti, Fabrizio, and Matthias Doepke (2012) 'Intergenerational Transmission of Risk Preferences, Entrepreneurship, and Growth.' 2012 Meeting Paper 246, Society for Economic Dynamics 